\title{
ON THE TERMINOLOGICAL MISTAKE IN THE BIOGRAPHY OF THE ASTRAKHAN COSSACK REGIMENT COMMANDER, MAJOR GENERAL P.S. POPOV ${ }^{1}$
}

\author{
Evgeniy V. Astafyev \\ Tsaritsyn Genealogical Society, Volgograd, Russian Federation
}

\begin{abstract}
On the basis of authentic documents of the late 18th - early 19th centuries, stored in federal and regional archives of Russia, as well as published materials, the article analyzes the reasons of the terminological mistake made in the biography of commander of Astrakhan's Cossack regiment, major general P.S. Popov, which had been reproduced in the scientific works for longer than 100 years.

So well known person in the Lower Volga region, P.S. Popov was purposefully chosen as an object of historical research. His biography is not typical for the people of provincial hereditary Russian nobility of this period, Astrakhan and Saratov's nobility in this case, where, although rather conventionally, he was linked for a long time in the historical literature.

Thanks to the current research, it was determined that P.S. Popov was born in Walachia, evidently not very rich noble family. For a long time he served in Bug Cossack regiment, where got promoted from Arnaut captain to officer rank. He took part in many campaigns of Russian-Turkish war, was repeatedly injured, and distinguished himself during the capture of the fortresses Ochakov and Ismail. P.S. Popov was awarded the order of St. John of Jerusalem, and golden mark for capture of Ismail.

P.S. Popov was married to a daughter of Astrakhan priest, and had seven sons and daughters in this spousal. Already serving in Astrakhan province, he purchased a seigneury for himself and descendants in Tsaritsyn district of the Saratov province. His descendants settled in the Lower Volga region, kept the seigneury in possession, served in military and civil services.

Key words: Volga nobility, Wallachia nobility, Saratov nobility, Astrakhan nobility, Arnaut captain, Astrakhan cossack warrior host, Bug Cossack regiment.
\end{abstract}

\section{О ТЕРМИНОЛОГИЧЕСКОЙ ОШИБКЕ В БИОГРАФИИ КОМАНДИРА АСТРАХАНСКОГО КАЗАЧЬЕГО ПОЛКА ГЕНЕРАЛ-МАЙОРА П.С. ПОПОВА ${ }^{1}$}

\author{
Евгений Владимирович Астафьев \\ Царицынское генеалогическое общество, г. Волгоград, Российская Федерация
}

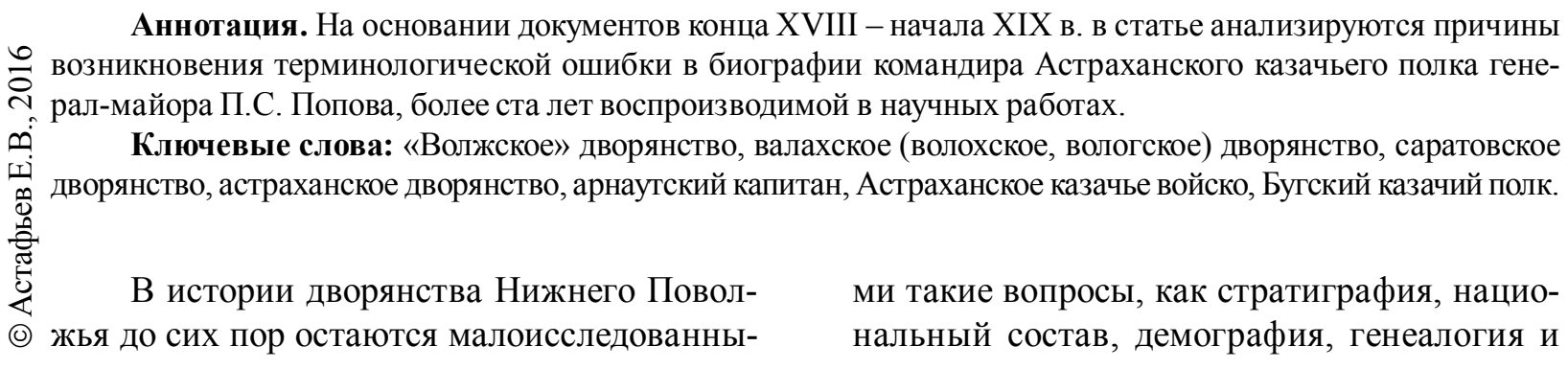


родственные связи, роль в колонизации региона. Наиболее проработанными являются вопросы о численности, землевладении и душевладении Саратовского и Астраханского дворянства XIX - начала XX вв. [17; 18; 19; 21; $22 ; 27 ; 33]$, тогда как в отношении XVIII в. эти проблемы почти не исследовались (см., напр.: $[20 ; 36])$. Примером тому является история рода Поповых. В литературе имеются работы, посвященные изучению дворянского казачьего рода Поповых ${ }^{2}$, внесенного как в Астраханские [6], так и в Саратовские [7] губернские дворянские родословные книги. Род этот дал многих блестящих офицеров Астраханскому казачьему войску и нескольких уездных предводителей Саратовскому дворянству ${ }^{3}$. При этом об основоположнике рода, генерал-майоре Павле Семеновиче Попове, достоверные биографические данные в исторической литературе до сих пор отсутствуют (см. подробнее: [4; 5; 11; 23; 34]).

Казалось бы, его жизнь и служба достаточно полно описаны в Русском биографическом словаре А.А. Половцовым [26, c. 566]. Эта информация уже более ста лет принимается научным сообществом как нечто само собой разумеющееся. Однако уже с первых строк данная биография должна была бы вызывать у читателя легкое замешательство некоторыми явными несоответствиями. Так, например, помимо путаницы в датах ${ }^{4}$ указано, что П.С. Попов, будучи выходцем «из Волжских дворян» 5 , поступил в 1771 г. на военную службу в Бугский казачий полк (о полке подробнее см.: [14, с. 16]) apнаутским капитаном, в 1781 г. был переведен полковым писарем, а в 1787 г. произведен прапорщиком. Таким образом, напрашиваются вопросы: почему выходцу из дворянской среды потребовалось так много лет для достижения офицерского чина и какова принадлежность этого загадочного, никогда не существовавшего «Волжского дворянства»? Очевидно, что ответ на один из этих вопросов должен дать ответ и на другой.

Итак, на первый взгляд, напрашивается связь определения «Волжское» - с гидронимом «Волга», либо происходящими от него Нижне-Волжскими топонимами и наименованиями: городом Волгском (Волжск, Вольск), Волжским казачьим войском и т. п.
Однако же топонима «Волгск» на момент рождения П.С. Попова еще не существовало, он был учрежден городом и переименован из села Малыковки [24, № 15080] почти тремя десятилетиями позднее - при создании Саратовского наместничества (губернии) [24, № 14967, 15080; 25, № 15126]; но даже после этого местное дворянство могло называться Волжским (Волгским) лишь в обиходе своей губернии, а на уровне Империи однозначно именовалось Саратовским дворянством. Значит, эта версия отпадает.

Вторая возможная гипотеза наводит на мысль: не бравада ли это заслуженного генерала, гордящегося своим происхождением из офицерских детей Волжского казачьего войска? Но территориально Волжское войско располагалось на землях Астраханской и, позднее, Саратовской губерний, соответственно, и дворянство также именовалось Астраханским или Саратовским, но никак не Волжским. Даже учитывая степень заслуг и высокое положение, сомнительно, чтобы такая вольность была допустима во времена весьма строгого отношения к определениям подобного рода. Кроме того, недавние исследования по истории Волжского казачьего войска А.В. Курышева, Т.И. Лавриновой и В.А. Гусева ставят под сомнение наличие в этом войске знатного рода с такой фамилией $[9 ; 10 ; 15 ; 16]$.

Далее эта гипотеза порождает две новые и весьма серьезные «нестыковки»: крайне странно, чтобы отпрыск из Волжской «старшины» вопреки традициям мог избрать для своей службы настолько удаленное, на тот момент довольно сомнительное и неперспективное, хотя и весьма обеспеченное в денежном плане, воинское формирование ${ }^{6}$. Но что еще удивительнее, так это то, чтобы казак из дворян - 16(!) лет ждал производства в прапорщики.

Так где же искать корни знаменитого генерала?

Из всех перечисленных А.А. Половцовым источников ${ }^{7}$ единственным способным прояснить происхождение термина «Волжское дворянство» оказалась астраханская газета «Восточные известия», напечатавшая некролог П.С. Попову. Некролог не смог пролить свет на происхождение П.С. Попова, однако 


\section{ОТЕЧЕСТВЕННАЯ ИСТОРИЯ}

все же дал ответ на загадочное появление слова «Волжских»: в нем на первой же странице сообщалось: «Родом он был из Воложких Дворян» [3, с. 1].

В Государственном архиве Саратовской области сохранилось дело о дворянском достоинстве рода Поповых [8]. Помимо этого, в одной из дворянских родословных книг за 1810-1813 гг. нам удалось обнаружить сведения о внесении П.С. Попова с сыновьями в дворянские списки Саратовской губернии [7, л. 40]. В обоих случаях о П.С. Попове написано «В воинскую службу вступил в Бугский казачий полк арнаутским капитаном (с 1.05.1771), переведен полковым писарем (c 15.09.1781), произведен прапорщиком (с 15.11.1787), полковым квартирмистром (с 15.01.1788) ...Именуется из Вологских дворян...»:

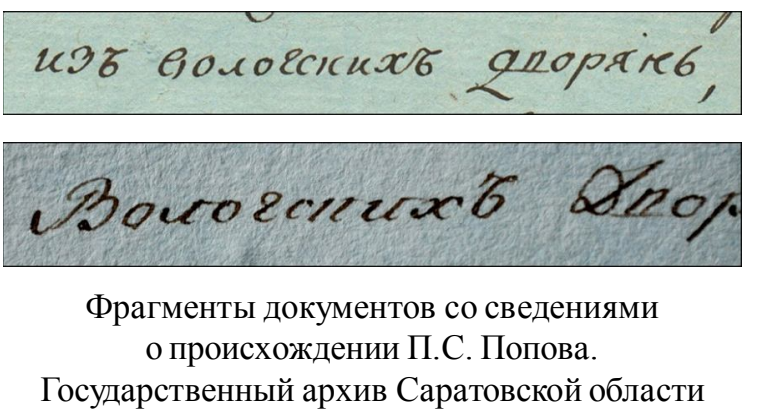

Аналогичная фраза имеется в документах Государственного архива Астраханской области ${ }^{8}[6]$ и Российского Государственного исторического архива [32]: «из Вологских дворян». Таким образом, мы имеем дело с простой ошибкой прочтения рукописного текста.

Однако снова вернемся к послужному списку П.С. Попова. Как, наконец, нам удалось определить, он явился уроженцем Валахии (Влахии), жителей которой европейцы называли «валахами», «влахами» или «волохами», поэтому, говоря о своем дворянском достоинстве, он просто сообщает: из Вологских (Волохских) дворян. Таким образом, логичным оказывается и выбор места службы в Бугском казачьем полку, а происхождение из Вологского (Волохского, Валахского) дворянства вполне объясняет столь долгий период пребывания в нижних чинах. Да и первая воинская должность П.С. Попова - «арнаутский капитан» - в данном сочетании может о3- начать как раз начальника (из благородного сословия) над командой добровольцев христианского происхождения, но не русского подданства, вступивших под русские знамена.

Что могло привести офицера из Бугского казачьего полка в Астраханский? Тут, учитывая временной период, участие П.С. Попова во взятии Очакова, оправданно предположить, что не обошлось без вмешательства одного из сподвижников Императрицы Екатерины II, фельдмаршала князя Г.А. Потемкина. В самом деле, такое участие, хотя, возможно, и не напрямую, имело место. Кроме того, ответ на этот вопрос, обнаруженный простым сопоставлением послужных списков двух командиров Астраханского казачьего полка, дополнительно подтвердился текстами уже упомянутого некролога в «Восточных известиях»: «...служил в Бугском Козачьем полку под командою Полковника (что после был Астраханским Гражданским Губернатором и Комендантом) Скаржинского», а также аттестата, выданного П.С. Попову около 1792 г. самим П.М. Скаржинским: «...по повелению покойнаго Его Светлости Высокоповелительного господина генерал-фельдмаршала князя Григорья Александровича Потемкина-Таврического переведен из Бугскаго казачьего в Аcтраханский казачей полк» $[8$, л. 4].

Действительно, Петр Михайлович Скаржинский командовал Вторым Бугским казачьим полком с 1785 по 1790 г. [35], участвовал в русско-турецкой войне и взятии Очакова, а 5 февраля 1790 г. был произведен Г.А. Потемкиным в чин бригадира и переведен на должность Астраханского обер-коменданта с поручением в его ведение Астраханского казачьего полка. Как мы знаем из послужного списка П.С. Попова, он получил чин капитана 10 февраля 1790 г. ${ }^{9}$, а затем сразу был переведен в Астраханский казачий полк, по-видимому, как один из ближайших соратников П.М. Скаржинского. В этом же году уже от Астраханского казачьего полка П.С. Попов снова был командирован к театру военных действий с турками, где отличился при взятии Измаила. 11 марта 1792 г. П.М. Скаржинский был назначен правителем Кавказского наместничества ${ }^{10}$, а на должность командира Астраханского казачьего полка вскоре официально был определен П.С. Попов. 
Таким образом, все несоответствия и неопределенности, возникшие в энциклопедической статье, оказались вполне логично разрешенными: не имея возможности проверить по другим источникам, но будучи прекрасно осведомлен о том, что потомки П.С. Попова впоследствии «осели» именно на Волге и были внесены в дворянские родословные книги Астраханской и Саратовской губерний, А.А. Половцов вынужден был принять ближайшее по звучанию и имеющее отношение к Астрахани наименование (которым и оказался уже упомянутый нами гидроним «Волга»), в итоге породив никогда не существовавший в действительности термин «Волжское дворянство».

\section{ПРИМЕЧАНИЯ}

1 Автор выражает благодарность за помощь и ценные рекомендации по теме работы своему научному руководителю, доктору исторических наук, профессору Игорю Олеговичу Тюменцеву, а также уважаемым коллегам: кандидату исторических наук И.Н. Плешакову (г. Саратов), кандидату исторических наук Н.В. Рыбалко (г. Волгоград), А.А. Шумкову (г. Санкт-Петербург), кандидату юридических наук А.Г. Костину (г. Москва), кандидату философских наук А.П. Высоцкому (г. Симферополь).

2 Один из известных родов в Нижнем Поволжье и вместе с тем один из многочисленных однофамильных Астраханских, Саратовских и Донских родов Поповых, в большинстве случаев не имеющих родственных связей.

${ }^{3}$ См. подробнее: [2, с. 49-50] и др.

4 В частности, приводится неизвестно откуда взявшаяся дата назначения П.С. Попова командиром Астраханского казачьего полка лишь 11 февраля 1801 г. вместо реальной даты 7 июня 1792 г.; указывается дата его смерти 12 мая вместо 14 мая 1815 г. (к сожалению, повторенная многими биографами, в том числе и на официальном интернет-сайте Астраханского государственного объединенного историко-архитектурного музея-заповедника) и т. д.

5 Подобное определение смущало, по-видимому, и самого А.А. Половцова, по этой причине даже взявшего его в кавычки.

${ }^{6}$ Всего за два года до этого перешедший на сторону России турецкий полк.

7 Ссылается сам на себя [1, с. 174]; упоминается только рапорт генерал-майора П.С. Попова от 1802 г. о прикочевании к российским границам большой партии киргиз-кайсацкого народа, а также несколько раз приводятся сведения о слушании Ко- митетом в 1809 г. дел о разграничении служебных обязанностей П.С. Попова как Командира Астраханского казачьего полка и споров по этому поводу с Астраханским гражданским губернатором [12, c. 24, 313-314, 324]; много и подробно описывается кордонная линия против киргиз, развитие и расширение ее при П.С. Попове и т. П., однако сведений о жизни и службе самого П.С. Попова практически не приводится [34]; здесь списки кавалеров различных орденов, но до наших дней сохранилась лишь малая часть эти дел, и все упоминаемые в них носители фамилии Попов не имеют отношения к интересующему нас П.С. Попову [28; 29; 30; 31]; лишь кратко упоминается о выбытии П.С. Попова из списков военных чинов в связи с его смертью [13]; опубликованы некролог и эпитафия П.С. Попову [3, с. 1].

${ }^{8}$ Нужно отметить, что в этом архиве документов по роду Поповых сохранилось несколько больше, чем в Саратовском, что, вероятно, объясняется местом службы и проживания членов семьи в начале XIX века.

9 Почти одновременно с получением бригадирского чина П.М. Скаржинским.

${ }^{10}$ Иногда в связи с этим имеет место употребление условного на тот момент термина «Астраханский губернатор».

\section{СПИСОК ЛИТЕРАТУРЫ}

1. Азбучный указатель имен Русских деятелей, имеющих быть помещенными в «Биографический словарь», издаваемый Императорским Русским Историческим Обществом // Сборник Императорского Русского исторического общества. - СПб. : Тип. Н.А. Лебедева, 1888. - Т. 62, ч. II : М-Ф. -825 с.

2. Астафьев, Е. В. Уездные Предводители Дворянства Аткарского, Камышинского и Царицынского уездов Саратовской губернии / Е. В. Астафьев // Нижне-Волжский исторический сборник Царицынского генеалогического общества. - Волгоград : Изд-во ЦГО, 2009. - Вып. 1. - С. 31-77.

3. Биография, взятая из послужного списка с присовокуплением речи и эпитафии (Некролог П.С. Попову) // Восточные известия. $-1815 .-29$ сент. (№ 39). - С. 1-4.

4. Бирюков, И. А. Астраханские казаки. Исторические очерки и рассказы. Географические, экономические и служебные сведения о войске / И. А. Бирюков. - Астрахань : [б. и.], 1904. -211 с.

5. Бирюков, И. А. История Астраханского казачьего войска: в 3 ч. / И. А. Бирюков. - Саратов : Типо-литография П. С. Феокритова, 1911. - Ч. 1.$1050 \mathrm{c}$.

6. Государственный архив Астраханской области. -Ф. 375. - Оп. 1. - Д. 172. - 107 л. 
7. Государственный архив Саратовской области (далее-ГАСО). - Ф. 19. - Оп. 1. - Д. 227.1. - 21 л.

8. ГАСО. -Ф. 19. -Оп. 1. - Д. 229. - 240 л.

9. Гусев, В. А. Поселение на Волге донских казаков / В. А. Гусев // Серия: Материалы по истории и генеалогии казачества. - Волгоград : Панорама, 2013. - Вып. 3. - 288 с.

10. Гусев, В. А. Сказочные казаки на Дону. Переселение на Терек сказочных и Волгских казаков / В. А. Гусев // Серия: Материалы по истории и генеалогии казачества. - Волгоград : Панорама, 2014. - Вып. 4. - 280 с.

11. Ершов, Л. Исторические и статистические сведения об Астраханском казачьем войске / Л. Ершов // Труды Астраханского губернского статистического комитета. - Астрахань : Астраханская губернская типография, 1869. - Вып. І. C. 57-100.

12. Извлечения из Журналов Комитета Министров за 1909 год // Журналы Комитета Министров. Царствование Императора Александра I. 18021826 гг. - СПб. : Тип. В. Безобразова и Ко, 1888. T. I : 1802-1810 гг. - С. 24-324.

13. Исключаются из списков // Русский инвалид. -1816. - № 55.

14. Казачьи войска / сост. В. Х. Казин ; под ред. В. К. Шенк. - СПб. : Тип. В.Д. Смирнова, 1912. -466 с.

15. Курышев, А. В. Волжское казачье войско (1730-1804): создание, развитие и преобразование в линейные казачьи полки / А. В. Курышев ; под ред. И. О. Тюменцева. - Волгоград : Издатель, 2011. -352 с.

16. Лавринова, Т. И. Царицынская линия: история строительства в 1718-1720 и первые годы существования / Т. И. Лавринова. - Волгоград : Издатель, 2012. - 95 с.

17. Нарцов, А. Н. Материалы для истории дворянских родов Мартыновых и Слепцовых с их ветвями (с гербами, портретами и таблицами) / А. Н. Нарцов. - Тамбов : Типо-литография губернского правления, 1904. $-987 \mathrm{c}$.

18. Наумов, А. В. Судьбы российского дворянства в XX веке : дис. ... канд. ист. наук / Наумов Алексей Викторович. - Саратов, 2009. - 230 с.

19. Николаев, К. А. Алфавитный список дворянских родов Астраханской губернии, внесенных в Дворянскую Родословную Книгу / К. А. Николаев. - Астрахань : Тип. «Рыбного дела» Н.Л. Рослякова, 1893. $-28 \mathrm{c}$.

20. Осипов, В. А. Очерки по истории колонизации Нижнего Поволжья во II-й половине XVIII века / В. А. Осипов. - Саратов : [б. и.], 1940. - 286 с.

21. Перечень дворянских родов Саратовской губернии / сост. О. К. Пудовочкина. - Саратов : ГАСО, 2002. $-30 \mathrm{c}$.

22. Платонова, Т. В. Дворянство Саратовской губернии в системе местного самоуправления (ко- нец XVIII - первая половина XIX века) / Т. В. Платонова. - Саратов : ПАГС, 2008. -48 с.

23. Плешаков, И. Н. Воинские части и учреждения в российской провинции во второй половине XVIII - начале XIX в. (по материалам Саратовского Поволжья) : дис. ... канд. ист. наук / Плешаков Иван Николаевич. - Саратов, 2009. - 180 с.

24. Полное собрание законов Российской Империи. - СПб. : Тип. ІІ Отд. Собств. ЕИВ Канцелярии, 1830. - Собр. 1, т. ХХ. - Док. 14967, 15080.

25. Полное собрание законов Российской Империи. - СПб. : Тип. IІ Отд. Собств. ЕИВ Канцелярии, 1830. - Собр. 1, т. XXI. - Док. 15126.

26. Попов, П. С. Биографическая статья // Русский биографический словарь / издан под наблюдением председателя Императорского Русского Исторического Общества А. А. Половцова. - СПб. : Тип. И.Н. Скороходова, 1905. - Т. 14. - С. 566.

27. Постников, С. В. Дворянский Вольск / С. В. Постников. - Саратов : Научная книга, 2008. $151 \mathrm{c}$.

28. Российский государственный исторический архив (далее-РГИА). -Ф. 496. -Оп. 1.-Д. 860. - 78 л.

29. РГИА. - Ф. 496. - Оп. 3. - Д. 1781. - 92 л.

30. РГИА. - Ф. 496. - Оп. 3. - Д. 1784. - 88 л.

31. РГИА. - Ф. 496. - Оп. 3. - Д. 2002. - 46 л.

32. РГИА. - Ф. 1343. - Оп. 27. - Д. 5605. - 63 л.

33. Семенов, В. Н. Саратов дворянский / В. Н. Семенов, Н. Н. Семенов. - Саратов : Приволжское книжное издательство, 2004. - 296 с.

34. Скворцов, В. Историко-статистический очерк Астраханского казачьего войска / В. Скворцов. - Саратов : Тип. П.С. Феокритова, 1890. - 411 с.

35. Сушинский, Б. И. Казацкие вожди Украины / Б. И. Сушинский. - Одесса : Вече, 2006. - Т. II -330 с.

36. Юровский, Л. Н. Саратовские вотчины. Статистико-экономические очерки и материалы из истории крупного землевладения и крепостного хозяйства в конце XVIII и в начале XIX столетия / Л. Н. Юровский. - Саратов : Издание Саратовского института народного хозяйства, 1923. $-230 \mathrm{c}$.

\section{REFERENCES}

1. Azbuchnyy ukazatel imen Russkikh deyateley, imeyushchikh byt pomeshchennymi v "Biograficheskiy slovar", izdavaemyy Imperatorskim Russkim Istoricheskim Obshchestvom [Alphabetical Index of Names of Russian Activists Placed in the "Biographical Dictionary", published by the Imperial Russian Historical Society]. Sbornik Imperatorskogo Russkogo istoricheskogo obshchestva [Collection of the Imperial Russian Historical Society]. Saint Petersburg, Tip. N.A. Lebedeva, 1888, vol. 62, part 2: M-F. 825 p. 
2. Astafyev E.V. Uezdnye Predvoditeli Dvoryanstva Atkarskogo, Kamyshinskogo i Tsaritsynskogo uezdov Saratovskoy gubernii [Leaders of Nobility in Atkarsk, Kamyshin and Tsaritsyn Districts of the Saratov Province]. Nizhne-Volzhskii istoricheskii sbornik Tsaritsynskogo genealogicheskogo obshchestva [Lower Volga Historical Collection of Tsaritsyn Genealogical Society]. Volgograd, Iz-vo TsGO, 2009, iss. 1, pp. 31-77.

3. Biografiya, vzyataya iz posluzhnogo spiska s prisovokupleniem rechi i epitafii (Nekrolog P.S. Popovu) [Biography From the Track Record With the Speech and the Epitaph (Obituary to P.S. Popov)]. Vostochnye izvestiya, 1815, Sept. 29 (no. 39), pp. 1-4.

4. Biryukov I.A. Astrakhanskie kazaki. Istoricheskie ocherki i rasskazy. Geograficheskie, ekonomicheskie i sluzhebnye svedeniya o voyske [Astrakhan Cossacks. Historical Essays and Short Stories. Geographical, Economic and Official Information About the Warrior Host]. Astrakhan, 1904. $211 \mathrm{p}$.

5. Biryukov I.A. Istoriya Astrakhanskogo kazachyego voyska: $v 3$ ch. [History of the Astrakhan Cossack Troops. In 3 Parts. Part 1]. Saratov, Tipolitografiya P.S. Feokritova, 1911. 1050 p.

6. Gosudarstvennyy arkhiv Astrakhanskoy oblasti [State Archive of the Astrakhan Region], F. 375, Op. 1, D. 172.107 p.

7. Gosudarstvennyy arkhiv Saratovskoy oblasti [State Archive of the Saratov Region], F. 19, Op. 1, D. 227.1.21 p.

8. Gosudarstvennyy arkhiv Saratovskoy oblasti [State Archive of the Saratov Region], F. 19, Op. 1, D. 229.240 p.

9. Gusev V.A. Poselenie na Volge donskikh kazakov [The Settlement of Don Cossacks in the Volga Region]. Seriya: Materialy po istorii $i$ genealogii kazachestva [Series: Materials on the History and Genealogy of the Cossacks]. Volgograd, Panorama Publ., 2013, iss. 3. 288 p.

10. Gusev V.A. Skazochnye kazaki na Donu. Pereselenie na Terek skazochnykh i Volzhskikh kazakov [Fabulous Cossacks on the Don. Resettlement of Fabulous and Volga Cossacks to the Terek River]. Seriya: Materialy po istorii i genealogii kazachestva Seriia: Materialy po istorii i genealogii kazachestva [Series: Materials on the History and Genealogy of the Cossacks]. Volgograd, Panorama Publ., 2014, iss. 4. 280 p.

11. Ershov L. Istoricheskie i statisticheskie svedeniia ob Astrakhanskom kazachyem voyske [Historical and Statistical Information About the Astrakhan Cossack Troops]. Trudy Astrakhanskogo gubernskogo statisticheskogo komiteta [Proceedings of the Astrakhan Regional Committee]. Astrakhan, Astrakhanskaya gubernskaya tipografiya Publ., 1869, iss. 1, pp. 57-100.
12. Izvlecheniya iz Zhurnalov Komiteta Ministrov za 1909 god [Extract From the Journals of the Committee of Ministers for 1909]. Zhurnaly Komiteta Ministrov. Tsarstvovanie Imperatora Aleksandra I. 1802-1826 $\mathrm{gg}$. [Journals of the Committee of Ministers. The Reign of Emperor Alexander I. 18021826]. Saint Petersburg, Tip. V. Bezobrazova i Ko, 1888, vol. I: 1802-1810, pp. 425-443.

13. Isklyuchayutsya iz spiskov [Excluded From the Lists]. Russkiy invalid, 1816, no. 55.

14. Kazin V.K. Kazachyi voyska [Cossack Troops]. Saint Petersburg, Tip. V.D. Smirnova, 1912. $466 \mathrm{p}$.

15. Kuryshev A.V. Volzhskoe kazachye voysko (1730-1804): sozdanie, razvitie i preobrazovanie v lineynye kazachyi polki [Volga Cossack Army (17301804): Creation, Development and Transformation into Linear Cossack Regiments]. Volgograd, Izdatel Publ., 2011.352 p.

16. Lavrinova T.I. Tsaritsynskaya liniya: istoriya stroitelstva $v$ 1718-1720 i pervye gody sushchestvovaniya [Tsaritsyn Guard Line: History of Construction in 1718-1720 and the First Years of Existence]. Volgograd, Izdatel Publ., 2012. 95 p.

17. Nartsov A.N. Materialy dlya istorii dvoryanskikh rodov Martynovykh $i$ Sleptsovykh s ikh vetvyami (s gerbami, portretami i tablitsami) [Materials for the History of the Martynovs and the Sleptsovs Noble Families and Their Branches (With Emblems, Portraits and Tables)]. Tambov, Tipo-litografiya gubernskogo pravleniya, 1904. 987 p.

18. Naumov A.V. Sudby rossiyskogo dvoryanstva v XX veke: dis. ... kand. ist. nauk [The Fates of the Russian Nobility in the Twentieth Century]. Saratov, 2009. 230 p.

19. Nikolaev K.A. Alfavitnyy spisok dvoryanskikh rodov Astrakhanskoy gubernii, vnesennykh $v$ Dvoryanskuyu Rodoslovnuyu Knigu [Alphabetical List of Noble Families of the Astrakhan Province Included in the Book of Noble Families]. Astrakhan, Tip. "Rybnogo dela" N.L. Roslyakova, 1893. 28 p.

20. Osipov V.A. Ocherki po istorii kolonizatsii Nizhnego Povolzhya vo II-y polovine XVIII veka [Essays on the History of the Colonization of the Lower Volga Region in the 2nd Half of the 18th Century]. Saratov, 1940. 286 p.

21. Pudovochkina O. K. Perechen dvoryanskikh rodov Saratovskoy gubernii [The List of Noble Families of the Saratov Province]. Saratov, GASO Publ., 2002. 30 p.

22. Platonova T.V. Dvoryanstvo Saratovskoy gubernii $v$ sisteme mestnogo samoupravleniya (konets XVIII-pervaya polovina XIX veka) [Gentry of the Saratov Province in the System of Local Government (End of 18th - First Half of 19th Century)]. Saratov, PAGS Publ., 2008. 48 p. 
23. Pleshakov I.N. Voinskie chasti i uchrezhdeniya $v$ rossiyskoy provintsii vo vtoroy polovine XVIII nachale XIX v. (po materialam Saratovskogo Povolzhya): dis. ... kand. ist. nauk [Military Units and Agencies in the Russian Province in the Second Half of 18th - early 19th Century (Based on the Materials of the Saratov Volga Region). Dr. hist. sci. diss.]. Saratov, 2009. $180 \mathrm{p}$.

24. Polnoe sobranie zakonov Rossiiskoy Imperii [Complete Collection of Laws of the Russian Empire]. Saint Petersburg, Tip. II Otd. Sobstv. EIV Kantselyarii Publ., 1830, Coll. 1, vol. 20, doc. 14967, 15080.

25. Polnoe sobranie zakonov Rossiiskoy Imperii [Complete Collection of Laws of the Russian Empire]. Saint Petersburg, Tip. II Otd. Sobstv. EIV Kantselyarii Publ., 1830, Coll. 1, vol. 21, doc. 15126.

26. Popov P.S. Biograficheskaya statya [Biographical Article]. Russkiy biograficheskiy slovar (izdan pod nablyudeniem predsedatelya Imperatorskogo Russkogo Istoricheskogo Obshchestva A. A. Polovtsova) [Russian Biographical Dictionary (Issued Under the Supervision of the Chairman of the Imperial Russian Historical Society A.A. Polovtsov]. Saint Petersburg, Tip. I.N. Skorokhodova Publ., 1905, vol. 14, p. 566.

27. Postnikov S.V. Dvoryanskiy Volsk [Noble Volsk]. Saratov, Nauchnaya kniga Publ., 2008. 151 p.

28. Rossiyskiy gosudarstvennyy istoricheskiy arkhiv [Russian State Historical Archive], F. 496, Op. 3, D. $860.78 \mathrm{p}$.
29. Rossiyskiy gosudarstvennyy istoricheskiy arkhiv [Russian State Historical Archive], F. 496, Op. 3, D. $1781.92 \mathrm{p}$.

30. Rossiyskiy gosudarstvennyy istoricheskiy arkhiv [Russian State Historical Archive], F. 496, Op. 3, D. $1784.88 \mathrm{p}$.

31. Rossiyskiy gosudarstvennyy istoricheskiy arkhiv [Russian State Historical Archive], F. 496, Op. 3, D. $2002.46 \mathrm{p}$.

32. Rossiyskiy gosudarstvennyy istoricheskiy arkhiv [Russian State Historical Archive], F. 1343, Op. 27, D. 5605.63 p.

33. Semenov V.N., Semenov N.N. Saratov dvoryanskiy [Noble Saratov]. Saratov, Privolzhskoe knizhnoe izdatelstvo, 2004. 296 p.

34. Skvortsov V. Istoriko-statisticheskiy ocherk Astrakhanskogo kazachyego voyska [Historical and Statistical Sketch of the Astrakhan Cossack Troops]. Saratov, Tip. P.S. Feokritova, 1890. 411 p.

35. Sushinskiy B.I. Kazatskie vozhdi Ukrainy [Cossack Leaders of Ukraine]. Odessa, Veche Publ., 2006, vol. 2. 330 p.

36. Yurovskiy L.N. Saratovskie votchiny. Statistiko-ekonomicheskie ocherki i materialy iz istorii krupnogo zemlevladeniya i krepostnogo khozyaystva $v$ kontse XVIII $i v$ nachale XIX stoletiya [Saratov Fiefdoms. Statistical and Economic Essays and Materials From the History of Large Estates and Serfdom in the Late 18th and Early 19th Centuries]. Saratov, Saratovskiy institut narodnogo khozyaystva, 1923.230 p.

\section{Information About the Author}

Evgeniy V. Astafyev, Chairman of Tsaritsyn Genealogical Society, Parkhomenko St., 47-B, 400050 Volgograd, Russian Federation, info@gen-volga.ru.

\section{Информация об авторе}

Евгений Владимирович Астафьев, председатель Царицынского генеалогического общества, ул. им. Пархоменко, 47-Б, 400050 г. Волгоград, Российская Федерация, info@gen-volga.ru. 